\title{
The SafeBoosC Phase II Randomised Clinical Trial: A Treatment Guideline for Targeted Near-Infrared- Derived Cerebral Tissue Oxygenation versus Standard Treatment in Extremely Preterm Infants
}

\author{
Adelina Pellicer ${ }^{a}$ Gorm Greisen ${ }^{b}$ Manon Benders ${ }^{c}$ Olivier Claris ${ }^{d}$ Eugene Dempsey ${ }^{e}$ \\ Monica Fumagalli ${ }^{f}$ Christian Gluud ${ }^{g}$ Cornelia Hagmann ${ }^{\mathrm{h}}$ Lena Hellström-Westas ${ }^{\mathrm{i}}$ \\ Simon Hyttel-Sorensen ${ }^{b}$ Petra Lemmers ${ }^{c}$ Gunnar Naulaers ${ }^{j}$ Gerhard Pichler ${ }^{k}$ \\ Claudia Roll' Frank van Bel ${ }^{c}$ Wim van Oeveren ${ }^{m}$ Maria Skoog ${ }^{g}$ Martin Wolf ${ }^{n}$ \\ Topun Austin $^{\circ}$ and the SafeBoosC Trial Group \\ aDepartment of Neonatology, La Paz University Hospital, Madrid, Spain; bepartment of Neonatology, \\ Rigshospitalet, Copenhagen University, Copenhagen, Denmark; ' Department of Neonatology, Universitair Medisch \\ Centrum, Wilhelmina Children's Hospital, Utrecht, The Netherlands; ${ }^{d}$ Department of Neonatology, Femme Mere \\ Enfants Hospital, Hospices Civils de Lyon, Lyon, France; ${ }^{\mathrm{e}}$ Department of Paediatrics and Child Health, University \\ College Cork, Cork, Ireland; ${ }^{f}$ Department of Clinical Sciences and Community Health, Fondazione IRCCS Ca' Granda \\ Ospedale Maggiore Policlinico Milan, Milan, Italy; ${ }^{9}$ Copenhagen Trial Unit, Centre for Clinical Intervention Research,

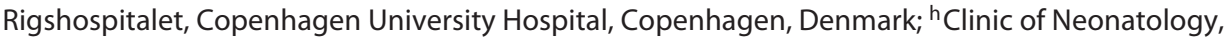 \\ University Hospital, Zurich, Switzerland; 'Department of Women's and Children's Health Uppsala Universitet, \\ Department of Neonatology, University Hospital, Uppsala, Sweden; ${ }^{j}$ Katholieke Universiteit Leuven, Leuven, Belgium; \\ kDepartment of Pediatrics, Medical University of Graz, Graz, Austria; 'Department of Neonatology and Paediatric \\ Intensive Care, Vest Children's Hospital Datteln, Datteln, Germany; ${ }^{\mathrm{m}}$ Haemoscan B.V., Groningen, The Netherlands; \\ ${ }^{n}$ Biomedical Optics Research Laboratory, Clinic of Neonatology, University Hospital, Zurich, Switzerland; \\ ${ }^{\circ}$ Rosie Maternity Hospital, University Hospitals NHS Foundation Trust, Cambridge, UK
}

\section{Key Words}

Near-infrared spectroscopy · Newborn · Practice guideline · Cardiovascular agents · Hypotension · Oxygen consumption · Carbon dioxide $\cdot$ Hyperoxia

\section{Abstract \\ Near-infrared spectroscopy-derived regional tissue oxygen saturation of haemoglobin $\left(\mathrm{rStO}_{2}\right)$ reflects venous oxygen saturation. If cerebral metabolism is stable, $\mathrm{rStO}_{2}$ can be used as an estimate of cerebral oxygen delivery. The SafeBoosC}

phase II randomised clinical trial hypothesises that the burden of hypo- and hyperoxia can be reduced by the combined use of close monitoring of the cerebral $\mathrm{rStO}_{2}$ and a treatment guideline to correct deviations in $\mathrm{rStO}_{2}$ outside a predefined target range. Aims: To describe the rationale for and content of this treatment guideline. Methods: Review of the literature and assessment of the quality of evidence and the grade of recommendation for each of the interventions. Results and Conclusions: A clinical intervention algorithm based on the main determinants of cerebral perfusion-oxygenation changes during the first hours after birth was gen-

\begin{tabular}{ll}
\hline KARGER & $\begin{array}{l}\text { (c) 2013 S. Karger AG, Basel } \\
\text { 1661-7800/13/1043-0171\$38.00/0 Operger }\end{array}$ \\
$\begin{array}{l}\text { E-Mail karger@karger.com } \\
\text { www.karger.com/neo }\end{array}$ & $\begin{array}{l}\text { This is an Open Access article licensed under the terms of the } \\
\text { Creative Commons Attribution-NonCommercial 3.0 Un- } \\
\text { ported license (CC BY-NC) (www.karger.com/OA-license), } \\
\text { applicable to the online version of the article only. Distribu- } \\
\text { tion permitted for non-commercial purposes only. }\end{array}$
\end{tabular}

Adelina Pellicer, $\mathrm{MD}, \mathrm{PhD}$

Department of Neonatology, La Paz University Hospital

Paseo de la Castellana 261

ES-28046 Madrid (Spain)

E-Mail apellicer.hulp@salud.madrid.org 
erated. The treatment guideline is presented to assist neonatologists in making decisions in relation to cerebral oximetry readings in preterm infants within the SafeBoosC phase II randomised clinical trial. The evidence grades were relatively low and the guideline cannot be recommended outside a research setting.

(c) 2013 S. Karger AG, Basel

\section{Introduction}

Abnormal haemodynamic adaptation during the transitional circulation together with the impact of respiratory distress syndrome and related factors on blood flow distribution [1] cause abnormalities in cerebral haemodynamics and oxygen supply [2-4]. Near-infrared spectroscopy (NIRS)-derived regional tissue oxygen saturation of haemoglobin $\left(\mathrm{rStO}_{2}\right)$ is an absolute value corresponding to mixed blood saturation, and can be used as a surrogate measure for venous oxygen saturation [5]. This allows the derivation of several variables related to tissue oxygen dynamics, such as oxygen delivery and consumption and the ratio between oxygen delivery to oxygen extraction, the so-called cerebral fractional oxygen extraction (FOE) $[5,6]$. Theoretically, therefore, this monitoring system could help to adjust interventions with effects on blood and oxygen supply to the brain.

The SafeBoosC phase II randomised clinical trial hypothesises that the burden of hypo- and hyperoxia can be reduced, and consequently the risk of brain injury, by the combined use of close monitoring of the cerebral $\mathrm{rStO}_{2}$ and an evidence-based treatment guideline to correct deviations in $\mathrm{rStO}_{2}$ outside a predefined target range [7-9]. Accordingly, a treatment guideline has been developed focusing on interventions that could have an impact on arterial oxygen saturation $\left(\mathrm{SaO}_{2}\right)$, haemoglobin concentration, and cerebral blood flow (CBF), which are the main determinants of oxygen delivery to the brain. The purpose of this report is to describe the rationale for this treatment guideline and the treatment recommendations.

\section{Interventions That Affect Oxygen Delivery to the Brain}

In drawing up the treatment guideline we used the premise that hypoxia and hyperoxia are risk factors for an adverse outcome in the preterm infant and should be avoided [10-15]. In addition to NIRS assessment of the cerebral circulation, a number of other techniques, par- ticularly echocardiography, are used to assess the neonatal transitional circulation and related outcomes [1, 1627]. For the purposes of the treatment guideline, a systematic review of the literature was carried out focusing on clinical studies conducted on human neonates that used NIRS-derived variables as outcome measures supporting the statements listed in the treatment guideline for intervention in the SafeBoosC phase II randomised clinical trial. The literature review was conducted in March 2011 using the database PubMed and subject headings (MeSH terms). There were no date restrictions. The search board was kept to combine the concept of a neonate (or newborn) with the concepts of NIRS and cerebrovascular circulation. In addition, blood pressure, hypotension, dopamine, dobutamine, epinephrine, anaemia, blood transfusion, carbon dioxide, respiratory distress syndrome, patent ductus arteriosus (PDA) and treatment, and blood glucose were also combined with the terms NIRS and newborn. This search was supplemented by cross references. Two hundred and twentynine abstracts were selected for review; among them, only $27 \%$ were relevant for the issues to be addressed in the treatment guideline. Only $4 \%$ of the selected studies were randomised clinical trials.

The proposed treatment guideline for the SafeBoosC phase II randomised clinical trial is based on interventions that may optimise cerebral oxygen supply and consumption through factors such as perfusion pressure, ventricular output, arterial oxygen content, arterial carbon dioxide, or blood glucose concentration. We assume a rather steady cerebral metabolic rate of oxygen. Given that the SafeBoosC intervention period focuses on the first 3 days after an extremely low gestational age neonate is born $[8,9]$, disease states and related factors most commonly present during that period were of particular interest. The definition of normal range for cerebral $\mathrm{rStO}_{2}$ in this trial (55-85\%) was derived from Lemmers and van $\mathrm{Bel}$ [unpubl. data] as the $95 \% \mathrm{CI}$ of $\mathrm{rStO}_{2}$ monitoring of 439 preterm infants born at $<32$ weeks during the first 3 days after birth using INVOS and the Adult SomaSensor (Somanetics-Covidien, Dublin, Ireland). The application of the adult sensor in this population is considered safe as no serious adverse device effects, such as skin burns, were found in these infants. Device eligibility will be tested by comparison of absolute values, reproducibility, and sensitivity to changes in oxygenation on the adult arm [28]. Absolute values and dynamic range within 5 percentage points of INVOS and reproducibility better than $6 \%$ are the predefined thresholds. So far, eligible devices for the SafeBoosC trial include INVOS 5100C with the Adult 
SomaSensor, NIRO 200NX (Hamamatsu Photonics, Fukuoka, Japan) with a small probe holder, and OxyPrem, a prototype developed by investigators in the SafeBoosC trial (M.W.).

We developed a pathophysiologically oriented, evidence-based treatment guideline and assessed the level of recommendation according to the US Preventive Services Task Force (USPSTF) System from 2001 [29] (Appendix). A new version of the USPSTF system is currently in use [30] where the wording of the grade $\mathrm{C}$ recommendation is possibly the most important change with respect to the previous version; it reads: '... against routinely providing $\mathrm{X}$ service for $\mathrm{Y}$ population; there may be considerations that support providing the service in an individual patient'. One of the actions listed in the present treatment guideline (i.e. volume expansion with normal saline) has been classified as a grade $\mathrm{C}$ recommendation. This, as well as the remaining actions included, is a suggested but not mandated intervention, and all of them should be considered individually according to the patient's overall clinical condition. Newer developments for grading the quality of evidence and the strength of recommendations [31] are more rigorous, but also more complex and time consuming. We, therefore, adhered to the USPSTF system due to its relative ease of use.

If $\mathrm{rStO}_{2}$ falls out of the normal range (55-85\%) and there is no reason to believe that it will normalise without an intervention, this treatment guideline aims to bring a standardised approach to correct the deviation. As the effect of certain interventions, such as the effect of cardiovascular drugs on blood pressure, are not expected to be immediate, it is recommended to choose only one intervention at a time and reassess after 30-60 min. It must be kept in mind that many routine care-giving procedures in the neonatal intensive care unit, such as handling or change in posture $[32,33]$, endotracheal tube repositioning or suctioning [32], or blood sampling from umbilical lines [34-36], among others, may have an impact on cerebral haemodynamics and oxygenation. However, since NIRS changes determined by these factors are usually transient and can be anticipated, they have not been listed in this treatment guideline.

Online supplementary figure 1 (for all online suppl. material, see www.karger.com/doi/1159/000351346) shows an algorithm that describes the flow of suggested interventions in the SafeBoosC trial when $\mathrm{rStO}_{2}$ is out of the target range.

$\mathrm{rStO}_{2}$ below the threshold may reflect compromised oxygen delivery. The proposed interventions are directed to increasing CBF, oxygen transport capacity, or blood

Treatment Guideline for Targeted

Cerebral Oxygenation oxygen content. Accordingly, the assessment of cardiovascular status, haemoglobin concentration, and $\mathrm{SaO}_{2}$ should be done before an intervention is chosen.

\section{Assessment/Interventions Related to Cardiovascular Status}

Changes in $\mathrm{rStO}_{2}$ or FOE may follow changes in cerebral perfusion pressure in infants with haemodynamic instability, which may [37-39] or may not [40-42] be reflected by concordant changes in mean arterial blood pressure. Thus, this treatment guideline would suggest to check the cardiovascular system, primarily considering clinical variables available in routine clinical practice, such as blood pressure, blood lactate concentration, capillary refill time, or urine output to define whether compromised systemic circulation is present or not. Echocardiography-derived variables on blood flow distribution, such as cardiac output and superior vena cava flow measurements, may be of value as complementary assessments to indicate or guide intervention.

Administration of fluid bolus, vasopressor-inotropes (dopamine or epinephrine), or inotropes (dobutamine), has a variable effect on blood pressure, cardiac performance, and cerebral perfusion-oxygenation [16-20, 43]. The effect of volume expansion on $\mathrm{rStO}_{2}$ has not been systematically explored in infants. However, a recent randomised clinical trial has shown that delayed cord clamping increases cerebral $\mathrm{rStO}_{2}$ at 4 and $24 \mathrm{~h}$ after birth in preterm infants [44]. This early increase in preload possibly ameliorates cardiovascular maladaptation during transitional circulation [45].

Studies in neonates have shown that dopamine [38, 43] and epinephrine [43], given to treat early systemic hypotension, increase cerebral perfusion-oxygenation. The 2-year follow-up of the study population showed comparable outcomes in vasopressor-inotrope-treated infants and infants who did not develop hypotension and thus did not receive cardiovascular support early after birth [16]. However, cautious use of vasopressors is recommended, as increased afterload may further compromise myocardial contractility causing additional decrease in cardiac output [1], and consequently, worsening cerebral perfusion.

The effect of a haemodynamically significant PDA or its treatment on cerebral haemodynamics and oxygenation is addressed in a number of studies using NIRS and other monitoring methods [46-61]. PDA may be a determinant in blood flow redistribution causing decreased blood pressure and $\mathrm{rStO} 2$ and increased FOE [57]. However, no correlation was found between ductal size and 
$\mathrm{rStO}_{2}$ [60]. Treatment of PDA may also be relevant for the $\mathrm{rStO}_{2}$ [57]. Indomethacin has been shown to have an acute greater impact on cerebral perfusion and oxygenation $[47,49,52,58,59]$ than ibuprofen $[51,52]$. However, slower infusion rates did not have such an impact on brain haemodynamics [61]. Surgical closure of the PDA showed no consistent effects on cerebral circulation and oxygenation [53-56].

Finally, mechanical factors, particularly lung overinflation, may decrease preload and cause increased pulmonary vascular resistance. Both factors would impair myocardial function and cardiac output [22-25]. This condition should always be ruled out in case of decreasing $\mathrm{rStO}_{2}$.

\section{Assessment/Interventions Related to Oxygen}

Transport (Blood Oxygen Carrying Capacity)

Although there is no clear correlation between haemoglobin concentration and tissue oxygen extraction [62, 63], packed-red cell transfusion improves cerebral oxygenation in the anaemic preterm infant [63-65]. In addition, a randomised clinical trial has shown that placentalto-foetal transfusion increases $\mathrm{rStO}_{2}$ [44], possibly not only due to increased oxygen carrying capacity but also to improved preload. A positive effect of this procedure on superior vena cava flow has been recently reported [45].

\section{Assessment/Interventions Related to Respiratory}

\section{Status}

Infants with respiratory distress syndrome have a significantly larger range of cerebral $\mathrm{rStO}_{2}$ and $\mathrm{FOE}$ and a stronger relation between these cerebral haemodynamic variables and mean arterial blood pressure than infants without respiratory distress syndrome [66]. One of the most important determinants of CBF and cerebral oxygen dynamics is partial pressure of carbon dioxide $\left(\mathrm{PCO}_{2}\right)$ $[46,63,67-70]$. It is crucial, because inadvertent hyperventilation may occur as a result of mechanical ventilation during the acute phase of respiratory distress syndrome. If $\mathrm{PCO}_{2}$ is below the normal range or low, even in the normal range, we recommend considering to decrease minute ventilation in case of low $\mathrm{rStO}_{2}[63,67-69]$. Since the effect of manipulating minute ventilation on $\mathrm{rStO}_{2}$ has not been tested in a randomised trial, the evidence level in this guideline is only II. The understanding of the mechanics and physiology, as well as the epidemiological link between hyperventilation and brain injury and cerebral palsy, however, may be seen as sufficient for a stronger recommendation $(\mathrm{A})$.

The effect of the type of mechanical ventilation or airway pressure on the cerebral haemodynamics and oxy- genation by NIRS has been the focus of some small observational studies in newborns [71-75]. The way these different methods affect intrathoracic pressures would likely impact the cerebral and systemic circulation of immature neonates [76].

This treatment guideline has been modified after a pilot trial [77] to specifically warn against exceeding the upper threshold of $\mathrm{SaO}_{2}$ according to local policies. Therefore, the fractional inspired oxygen fraction $\left(\mathrm{FiO}_{2}\right)$ should only be increased if $\mathrm{SaO}_{2}$ is below the normal range or low, even in the normal range [10]. Other potential actions relate to increasing $\mathrm{SaO}_{2}$ through improvement in lung recruitment by moderate increase in mean airway pressure $[22,26,75]$.

$\mathrm{rStO}_{2}$ increasing above the upper normal limit may reflect impaired oxygen utilisation or disturbed cerebral autoregulation, and interventions should be directed at decreasing hyperaemia. The assessment of respiratory status and blood glucose content should be done before an intervention is chosen.

\section{Assessment/Interventions Related to Respiratory \\ Status}

The first step would be decrease $\mathrm{FiO}_{2}$ in case $\mathrm{SaO}_{2}$ is above the normal range or high, even in the normal range [11-15]. Additional interventions would be to decrease mean airway pressure $[26,75]$. The vasodilator effect of $\mathrm{PCO}_{2}$ should be considered, so minute ventilation should be increased in case of $\mathrm{PCO}_{2}$ above the normal range or high, even in the normal range, to lower $\mathrm{PCO}_{2}[63,67-69]$.

\section{Assessment of Blood Glucose Level}

Hypoglycaemia would be the cause of capillary recruitment and increased CBF $[27,78]$. Thus, if the blood glucose level is below the normal range or low, even in the normal range, increased glucose intake should be considered to raise blood glucose concentration.

\section{Conclusion}

This treatment guideline for the SafeBoosC phase II trial aims to help neonatologists to take decisions in relation to cerebral oximetry readings. None of the suggested actions are mandatory. The proposed clinical intervention algorithm is focused on the main determinants of cerebral perfusion-oxygenation changes during the first hours after birth in the extremely low gestational age neonate population, and is thus pathophysiologically 
oriented. The evidence supporting some of these statements is generally rather weak. The proposed interventions, however, are all routinely used in clinical care of these patients. Particular care has been taken on hyperventilation with low $\mathrm{PCO}_{2}$ and oxygen administration with high $\mathrm{SaO}_{2}$ due to their association with adverse outcomes. We stress that this guideline is not approved for general use outside randomised clinical trials. We look forward to be able to report the results of the present SafeBoosC phase II randomised clinical trial and the planned SafeBoosC phase III randomised clinical trial that will evaluate the combined effect of NIRS and this treatment guideline $[8,9]$.

\section{Acknowledgements}

The authors acknowledge the financial support of the Danish Council for Strategic Research for the SafeBoosC phase II randomised clinical trial.

\section{Disclosure Statement}

The authors have no potential conflict of interest.

\section{Appendix}

\section{SafeBoosC Trial Treatment Guideline}

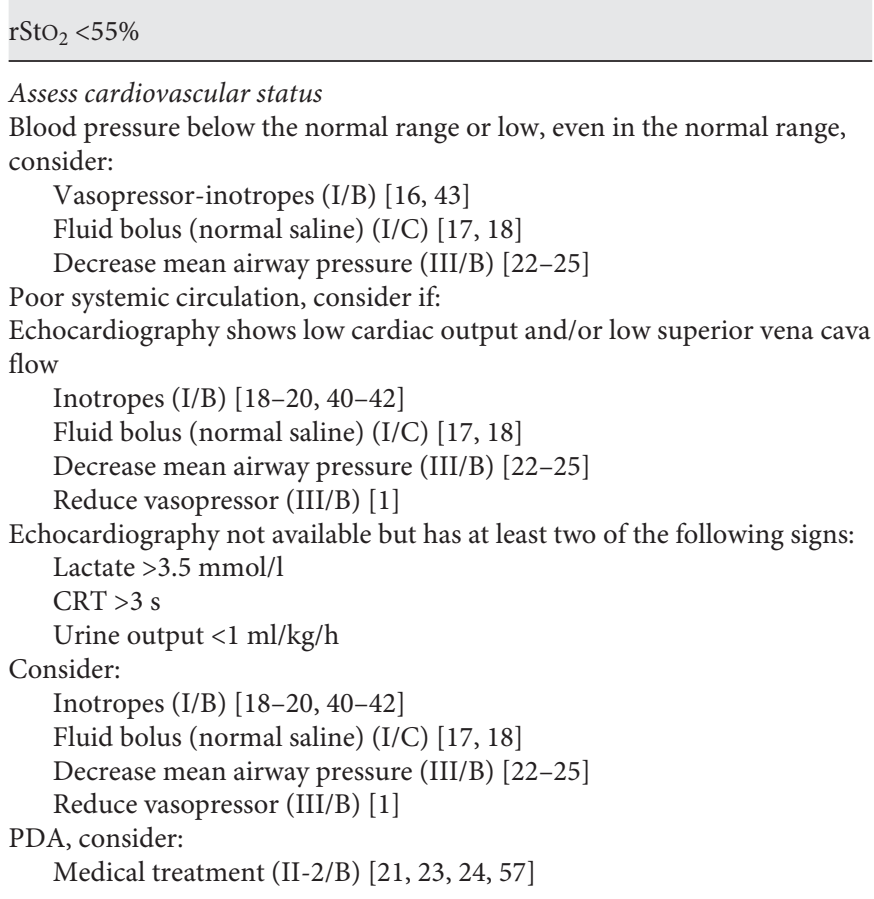

Treatment Guideline for Targeted

Cerebral Oxygenation

Assess oxygen transport

Haemoglobin below the normal range or low, even in the normal range, consider:

Red blood cell transfusion (I/B) [44, 63-65]

Assess respiratory status

$\mathrm{SaO}_{2}$ below the normal range or low, even in the normal range, consider: Increase $\mathrm{FiO}_{2}$ (II-1/A) [10] (attention: be careful not to exceed the upper target threshold of $\left.\mathrm{SaO}_{2}\right)$ Increase mean airway pressure (III/B) [22, 26, 75]

$\mathrm{PCO}_{2}$ below the normal range or low, even in the normal range, consider: Decrease minute ventilation (II-2/A) [63, 67-69]

$\mathrm{rStO}_{2}>85 \%$

Assess respiratory status

$\mathrm{SaO}_{2}$ above the normal range or high, even in the normal range, consider: Decrease $\mathrm{FiO}_{2}$ (II-2/A) [11-15]

Decrease mean airway pressure (III/B) $[26,75]$

$\mathrm{PCO}_{2}$ above the normal range or high, even in the normal range, consider: Increase minute ventilation (II-2/A) [63, 67-69]

Assess blood glucose level

Blood glucose $<2.5 \mathrm{mmol} / \mathrm{l}$, consider: Increase glucose intake (II-2/A) [27, 78]

The recommendation according to the US Preventive Services Task Force (USPSTF) System for 20001 [29]. The Roman number refers to the level of evidence hierarchy the recommendation originates from (I; II-1; II-2; II-3; III) and the letter is our recommendation according to the USPSTF grading $(\mathrm{A} ; \mathrm{B} ; \mathrm{C} ; \mathrm{D} ; \mathrm{I})$.

Level of Type of study evidence

I evidence obtained from at least one properly randomised controlled trial

II-1 evidence obtained from well-designed controlled trials without randomisation

II-2 evidence obtained from well-designed cohort or case-control analytic studies, preferably from more than one centre or research group

II-3 evidence obtained from multiple time series with or without intervention; dramatic results in uncontrolled experiments (such as the results of the introduction of penicillin treatment in the 1940s) can also be regarded as this type of evidence

III opinions of respected authorities, based on clinical experience, descriptive studies and case reports, or reports of expert committees 


\begin{tabular}{lllll}
\hline Quality of evidence & \multicolumn{2}{l}{ Net benefit } & & \\
\cline { 2 - 5 } & substantial & moderate & small & zero/negative \\
\hline Good & A & B & C & D \\
\hline Fair & B & B & C & D \\
\hline
\end{tabular}

Poor $=\mathrm{I}$

Standard recommendation $\quad \mathrm{A}=$ strongly recommended (good evidence that the intervention improves important health outcomes language and benefits substantially outweigh harms)

$\mathrm{B}=$ recommended (at least fair evidence that the intervention improves important health outcomes and benefits substantially outweigh harms)

$\mathrm{C}=$ no recommendation for or against routine provision of the intervention (fair evidence that the service can improve health outcomes but the balance of the benefits and harms is too close to justify a general recommendation)

$\mathrm{D}=$ recommends against routinely providing the intervention (at least fair evidence that the service is ineffective or that harms outweigh benefits)

$\mathrm{I}=$ insufficient to recommend for or against routinely providing the intervention (evidence that the intervention is effective is lacking, of poor quality, or conflicting and the balance of benefits and harms cannot be determined)

\section{References}

1 Kluckow M, Seri I: Clinical presentations of neonatal shock: the VLBW infant during the first postnatal day; in Kleinman CS, Seri I (eds): Hemodynamics and Cardiology. Neonatology Questions and Controversies. Philadelphia, Saunders, 2008, pp 147-177.

2 Osborn DA, Evans N, Kluckow M: Hemodynamic and antecedent risk factors of early and late periventricular/intraventricular hemorrhage in premature infants. Pediatrics 2003; 112:33-39.

3 Meek JH, Tyszczuk L, Ellwell CE, Wyatt JS: Low cerebral blood flow is a risk factor for severe intraventricular haemorrhage. Arch Dis Child Fetal Neonatal Ed 1999;81:F15-F18.

4 Goldstein RF, Thompson RJ Jr, Oehler JM, Brazy JE: Influence of acidosis, hypoxemia, and hypotension on neurodevelopmental outcome in very low birth weight infants. Pediatrics 1995;95:238-243.

5 Pellicer A, Bravo MC: Near-infrared spectroscopy: a methodology focused-review. Semin Fetal Neonatal Med 2011;16:42-49.

6 Yoxall CW, Weindling AM: Measurement of cerebral oxygen consumption in the human neonate using near infrared spectroscopy: cerebral oxygen consumption increases with advancing gestational age. Pediatr Res 1998; 44:283-290.

$>7$ Greisen G, Leung T, Wolf M: Has the time come to use near-infrared spectroscopy as a routine clinical tool in preterm infants undergoing intensive care? Philos Transact A Math Phys Eng Sci 2011;369:4440-4451.

8 SafeBoosC phase II trial group. http://www. clinicaltrials.gov/ct2/results?term=NCT0190316.
9 Hyttel-Sorensen S, Austin T, van Bel F, Benders M, Claris O, Dempsey E, Fumagalli M, Greisen G, Grevstad B, Hagmann C, Hellström-Westas L, Lemmers P, Lindschou Hansen J, Naulaers G, van Oeveren W, Pellicer A, Pichler G, Roll C, Skoog M, Winkel P, Wolf M, Gluud C: SafeBoosC: a randomised clinical phase II trial on cerebral near infrared spectroscopy on extremely preterm infants during the first three days - the protocol. Trials 2013;14:120

10 Schulze A, Whyte RK, Way RC, Sinclair JC: Effect of the arterial oxygenation level on cardiac output, oxygen extraction, and oxygen consumption in low birth weight infants receiving mechanical ventilation. J Pediatr 1995; 126:777-784.

11 Collins MP, Lorenz JM, Jetton JR, Paneth N: Hypocapnia and other ventilation related risk factors for cerebral palsy in low birth weight infants. Pediatr Res 2001;50:712-719.

12 Tin W, Milligan DWA, Pennefather P, Hey E: Pulse oximetry, severe retinopathy and outcome at one year in babies of less than 28 weeks gestation. Arch Dis Child Fetal Neonatal Ed 2001;84:F106-F110.

13 Chow L, Wright KW, Sola A: Can changes in clinical practice decrease the incidence of severe retinopathy in very low birth weight infants? Pediatrics 2003;111:339-345.

14 Anderson CG, Benitz WE, Madan A: Retinopathy of prematurity and pulse oximetry: a national survey of recent practices. J Perinatol 2004;24:164-168.
15 SUPPORT Study Group of the Eunice Kennedy Shriver NICHD Neonatal Research Network, Carlo WA, Finer NN, Walsh MC, et al: Target ranges of oxygen saturation in extremely preterm infants. N Engl J Med 2010; 362:1959-1969.

16 Pellicer A, Bravo MC, Madero R, Salas S, Quero J, Cabañas F: Early systemic hypotension and vasopressor support in low birth weight infants: impact on neurodevelopment. Pediatrics 2009;123:1369-1376.

17 Lundstrom K, Pryds O, Greisen G: The haemodynamic effects of dopamine and volume expansion in sick preterm infants. Early Hum Dev 2000;57:157-163.

18 Osborn D, Evans N, Kluckow M: Randomized trial of dobutamine versus dopamine in preterm infants with low systemic blood flow. J Pediatr 2002;140:183-191.

19 Osborn DA, Evans N, Kluckow M, Bowen JR, Rieger I: Low superior vena cava flow and effect of inotropes on neurodevelopment to 3 years in preterm infants. Pediatrics 2007;120: 372-380.

20 Osborn DA, Paradisis M, Evans N: The effect of inotropes on morbidity and mortality in preterm infants with low systemic or organ blood flow. Cochrane Database Syst Rev 2007; 1:CD005090.

-21 Jim WT, Chiu NC, Chen MR, Hung HY, Kao $\mathrm{HA}$, Hsu CH, Chang JH: Cerebral hemodynamic change and intraventricular hemorrhage in very low birth weight infants with patent ductus arteriosus. Ultrasound Med Biol 2005;31:197-202. 
-22 Trang TT, Tibballs J, Mercier JC, Beaufils F: Optimization of oxygen transport in mechanically ventilated newborns using oximetry and pulsed Doppler-derived cardiac output. Crit Care Med 1988;16:1094-1097.

23 Skinner JR, Boys RJ, Hunter S, Hey EN: Pulmonary and systemic arterial pressure in hyaline membrane disease. Arch Dis Child 1992; 67:366-373.

24 Evans N, Kluckow M: Early determinants of right and left ventricular output in ventilated preterm infants. Arch Dis Child Fetal Neonatal Ed 1996;74:F88-F94.

25 Kluckow M, Evans N: Relationship between blood pressure and cardiac output in preterm infants requiring mechanical ventilation. J Pediatr 1996;129:506-512.

26 de Waal KA, Evans N, Osborn DA, Kluckow $\mathrm{M}$ : Cardiorespiratory effects of changes in end expiratory pressure in ventilated newborns. Arch Dis Child Fetal Neonatal Ed 2007;92:F444-F448.

27 Pryds O, Christensen NJ, Friis-Hansen B: Increased cerebral blood flow and plasma epinephrine in hypoglycemic preterm neonates. Pediatrics 1990;85:172-176.

-28 Hyttel-Sorensen S, Sorensen LC, Riera J, Greisen G: Tissue oximetry: a comparison of mean values of regional tissue saturation, reproducibility and dynamic range of four NIRS-instruments on the human forearm. Biomed Opt Express 2011;2:3047-3057.

29 Harris RP, Helfand M, Woolf SH, Lohr KN, Mulrow CD, Teutsch SM, Atkins D, Methods Work Group, Third US Preventive Services Task Force: Current methods of the US Preventive Services Task Force: a review of the process. Am J Prev Med 2001;20:21-35.

30 Barton MB, Miller T, Wolff T, Petitti D, Le Fevre M, Sawaya G, Yawn B, Guirguis-Blake J, Calonge N, Harris R, US Preventive Services Task Force: How to read the new recommendation statement: methods update from the U.S. Preventive Services Task Force. Ann Intern Med 2007;147:123-127.

31 GRADE Working Group: Grading quality of evidence and strength of recommendations. BMJ 2004;328:1490-1494.

- 32 Limperopoulos C, Gauvreau KK, O'Leary H, Moore M, Bassan H, Eichenwald EC, Soul JS, Ringer SA, Di Salvo DN, du Plessis AJ: Cerebral hemodynamic changes during intensive care of preterm infants. Pediatrics 2008; 122:e1006-e1013.

-33 Pellicer A, Gayá F, Madero R, Quero J, Cabañas F: Noninvasive continuous monitoring of the effects of head position on brain hemodynamics in ventilated infants. Pediatrics 2002 109:434-440.

- 34 Schulz G, Keller E, Haensse D, Arlettaz R, Bucher HU, Fauchère JC: Slow blood sampling from an umbilical artery catheter prevents a decrease in cerebral oxygenation in the preterm newborn. Pediatrics 2003;111:e73-e76.
35 Roll C, Hüning B, Käunicke M, Krug J, Horsch S: Umbilical artery catheter blood sampling volume and velocity: impact on cerebral blood volume and oxygenation in verylow-birthweight infants. Acta Paediatr 2006; 95:68-73.

36 Hüning BM, Horsch S, Roll C: Blood sampling via umbilical vein catheters decreases cerebral oxygenation and blood volume in preterm infants. Acta Paediatr 2007;96:16171621.

37 Tsuji M, Saul JP, du Plessis A, Eichenwald E, Sobh J, Crocker R, Volpe JJ: Cerebral intravascular oxygenation correlates with mean arterial pressure in critically ill premature infants. Pediatrics 2000;106:625-632.

38 Munro MJ, Walker AM, Barfield CP: Hypotensive extremely low birth weight infants have reduced cerebral blood flow. Pediatrics 2004;114:1591-1596.

39 Wong FY, Leung TS, Austin T, Wilkinson M, Meek JH, Wyatt JS, Walker AM: Impaired autoregulation in preterm infants identified by using spatially resolved spectroscopy. Pediatrics 2008;121:e604-e611.

40 Takami T, Sunohara D, Kondo A, Mizukaki N, Suganami Y, Takei Y, Miyajima T, Hoshika A: Changes in cerebral perfusion in extremely LBW infants during the first $72 \mathrm{~h}$ after birth. Pediatr Res 2010;68:435-439.

-41 Moran M, Miletin J, Pichova K, Dempsey EM: Cerebral tissue oxygenation index and superior vena cava blood flow in the very low birth weight infant. Acta Paediatr 2009;98:43-46.

42 Kissack CM, Garr R, Wardle SP, Weindling AM: Cerebral fractional oxygen extraction in very low birth weight infants is high when there is low left ventricular output and hypocarbia but is unaffected by hypotension. Pediatr Res 2004;55:400-405.

43 Pellicer A, Valverde E, Elorza MD, Madero R, Gayá F, Quero J, Cabañas F: Cardiovascular support for low birth weight infants and cerebral hemodynamics: a randomized, blinded, clinical trial. Pediatrics 2005;115:1501-1512.

44 Baenziger O, Stolkin F, Keel M, von Siebenthal K, Fauchere JC, Das Kundu S, Dietz V, Bucher HU, Wolf M: The influence of the timing of cord clamping on postnatal cerebral oxygenation in preterm neonates: a randomized, controlled trial. Pediatrics 2007;119: 455-459.

45 Sommers R, Stonestreet BS, Oh W, Laptook A, Yanowitz TD, Raker C, Mercer J: Hemodynamic effects of delayed cord clamping in premature infants. Pediatrics 2012;129:e667e672.

46 Adcock LM, Wafelman LS, Hegemier S, Moise AA, Speer ME, Contant CF, Goddard-Finegold J: Neonatal intensive care applications of near-infrared spectroscopy. Clin Perinatol 1999;26:893-903.

47 Edwards AD, Wyatt JS, Richardson C, Potter A, Cope M, Delpy DT, Reynolds EO: Effects of indomethacin on cerebral haemodynamics in very preterm infants. Lancet 1990;335: 1491-1495.
48 Naulaers G, Delanghe G, Allegaert K, Debeer A, Cossey V, Vanhole C, Casaer P, Devlieger $\mathrm{H}$, Van Overmeire B: Ibuprofen and cerebral oxygenation and circulation. Arch Dis Child Fetal Neonatal Ed 2005;90:F75-F76.

-49 Keating P, Verhagen E, van Hoften J, ter Horst H, Bos AF: Effect of indomethacin infused over $30 \mathrm{~min}$ on cerebral fractional tissue oxygen extraction in preterm newborns with a patent ductus arteriosus. Neonatology 2010; 98:232-237.

50 Underwood MA, Milstein JM, Sherman MP: Near-infrared spectroscopy as a screening tool for patent ductus arteriosus in extremely low birth weight infants. Neonatology 2007; 91:134-139.

51 Patel J, Roberts I, Azzopardi D, Hamilton P, Edwards AD: Randomized double-blind controlled trial comparing the effects of ibuprofen with indomethacin on cerebral hemodynamics in preterm infants with patent ductus arteriosus. Pediatr Res 2000;47:36-42.

52 Mosca F, Bray M, Lattanzio M, Fumagalli M, Tosetto C: Comparative evaluation of the effects of indomethacin and ibuprofen on cerebral perfusion and oxygenation in preterm infants with patent ductus arteriosus. J Pediatr 1997;131:549-554.

-53 Hüning BM, Asfour B, König S, Hess N, Roll C: Cerebral blood volume changes during closure by surgery of patent ductus arteriosus. Arch Dis Child Fetal Neonatal Ed 2008; 93:F261-F264.

54 Zaramella P, Freato F, Quaresima V, Ferrari M, Bartocci M, Rubino M, Falcon E, Chiandetti L: Surgical closure of patent ductus arteriosus reduces the cerebral tissue oxygenation index in preterm infants: a near-infrared spectroscopy and Doppler study. Pediatr Int 2006;48:305-312.

55 Lemmers PM, Molenschot MC, Evens J, Toet $\mathrm{MC}$, van Bel F: Is cerebral oxygen supply compromised in preterm infants undergoing surgical closure for patent ductus arteriosus? Arch Dis Child Fetal Neonatal Ed 2010; 95:F429-F434.

56 Vanderhaegen J, De Smet D, Meyns B, Van De Velde M, Van Huffel S, Naulaers G: Surgical closure of the patent ductus arteriosus and its effect on the cerebral tissue oxygenation. Acta Paediatr 2008;97:1640-1644.

57 Lemmers PM, Toet MC, van Bel F: Impact of patent ductus arteriosus and subsequent therapy with indomethacin on cerebral oxygenation in preterm infants. Pediatrics 2008;121: 142-147.

58 Benders MJ, Dorrepaal CA, van de Bor M, van Bel F: Acute effects of indomethacin on cerebral hemodynamics and oxygenation. Biol Neonate 1995;68:91-99.

59 Liem KD, Hopman JC, Kollée LA, Oeseburg $B$ : Effects of repeated indomethacin administration on cerebral oxygenation and haemodynamics in preterm infants: combined near infrared spectrophotometry and Doppler ultrasound study. Eur J Pediatr 1994;153:504509, erratum Eur J Pediatr 1994;153:782.
Treatment Guideline for Targeted Cerebral Oxygenation
Neonatology 2013;104:171-178 DOI: $10.1159 / 000351346$ 
60 Petrova A, Bhatt M, Mehta R: Regional tissue oxygenation in preterm born infants in association with echocardiographically significant patent ductus arteriosus. J Perinatol 2011;31:460-464.

61 Christmann V, Liem KD, Semmerkrot BA, van de Bor M: Changes in cerebral, renal, and mesenteric blood flow velocity during continuous and bolus infusion of indomethacin. Acta Paediatr 2002;91:440-446.

-62 Bailey SM, Hendricks-Muñoz KD, Wells JT, Mally P: Packed red blood cell transfusion increases regional cerebral and splanchnic tissue oxygen saturation in anemic symptomatic preterm infants. Am J Perinatol 2010;27: 445-453.

63 Wardle SP, Yoxall CW, Weindling AM: Determinants of cerebral fractional oxygen extraction using near infrared spectroscopy in preterm neonates. J Cereb Blood Flow Metab 2000;20:272-279.

64 Dani C, Pezzati M, Martelli E, Prussi C, Bertini G, Rubaltelli FF: Effect of blood transfusions on cerebral haemodynamics in preterm infants. Acta Paediatr 2002;91:938-941.

65 Dani C, Pratesi S, Fontanelli G, Barp J, Bertini G: Blood transfusions increase cerebral, splanchnic, and renal oxygenation in anemic preterm infants. Transfusion 2010;50:12201226.

66 Lemmers PM, Toet M, van Schelven LJ, van Bel F: Cerebral oxygenation and cerebral oxygen extraction in the preterm infant: the impact of respiratory distress syndrome. Exp Brain Res 2006;173:458-467.
67 Pryds O, Greisen G, Skov LL, Friis-Hansen B: Carbon dioxide-related changes in cerebral blood volume and cerebral blood flow in mechanically ventilated preterm neonates: comparison of near infrared spectrophotometry and 133Xenon clearance. Pediatr Res 1990;27: 445-449.

68 Dietz V, Wolf M, Keel M, v Siebenthal K, Baenziger $\mathrm{O}$, Bucher $\mathrm{H}: \mathrm{CO}_{2}$ reactivity of the cerebral hemoglobin concentration in healthy term newborns measured by near infrared spectrophotometry. Biol Neonate 1999;75: 85-90.

69 Vanderhaegen J, Naulaers G, Vanhole C, De Smet D, Van Huffel S, Vanhaesebrouck S, Devlieger $\mathrm{H}$ : The effect of changes in $\mathrm{tPCO}_{2}$ on the fractional tissue oxygen extraction - as measured by near-infrared spectroscopy in neonates during the first days of life. Eur J Paediatr Neurol 2009;13:128-134.

70 Mosca F, Bray M, Colnaghi MR, Fumagalli M, Compagnoni G: Cerebral vasoreactivity to arterial carbon dioxide tension in preterm infants: the effect of ibuprofen. J Pediatr 1999; 135:644-646.

71 Zaramella P, Freato F, Grazzina N, Saraceni E, Vianello A, Chiandetti L: Does helmet CPAP reduce cerebral blood flow and volume by comparison with Infant Flow driver CPAP in preterm neonates? Intensive Care Med 2006; 32:1613-1619.

72 Palmer KS, Spencer SA, Wickramasinghe YA, Wright T, Southall DP, Rolfe P: Effects of positive and negative pressure ventilation on cerebral blood volume of newborn infants. Acta Paediatr 1995;84:132-139.
73 Dani C, Bertini G, Cecchi A, Corsini I, Pratesi S, Rubaltelli FF: Brain haemodynamic effects of nasal continuous airway pressure in preterm infants of less than 30 weeks' gestation. Acta Paediatr 2007;96:1421-1425.

74 Noone MA, Sellwood M, Meek JH, Wyatt JS: Postnatal adaptation of cerebral blood flow using near infrared spectroscopy in extremely preterm infants undergoing high-frequency oscillatory ventilation. Acta Paediatr 2003;92: 1079-1084.

75 Cantagrel S, Cloarec S, Suc AL, Chamboux C, Tessier V, Saliba E, Laugier J: Consequences of pulmonary inflations (sighs) on cerebral haemodynamics in neonates ventilated by high-frequency oscillation. Acta Paediatr 1999;88:1004-1008.

76 Valverde E, Pellicer A, Madero R, Elorza D, Quero J, Cabañas F: Dopamine versus epinephrine for cardiovascular support in low birth weight infants: analysis of systemic effects and neonatal clinical outcomes. Pediatrics 2006;117:e1213-e1222.

77 Hyttel-Sorensen S, Austin T, van Bel F, Benders M, Claris O, Dempsey E, Fumagalli M, Gluud C, Hagmann C, Hellström-Westas L, Lemmers P, Naulaers G, van Oeveren W, Pellicer A, Pichler G, Roll C, Saem Stoy L, Greisen G: Clinical use of cerebral oximetry in extremely preterm infants is feasible. Dan Med J 2013;60:A4533.

78 Skov L, Pryds O: Capillary recruitment for prevention of cerebral glucose influx in hypoglycemic, preterm newborns: evidence for a glucose sensor? Pediatrics 1992;90:193-195. 